\title{
Taxonomic Dissection of the Genus Micrococcus: Kocuria gen. nov., Nesterenkonia gen. nov., Kytococcus gen. nov., Dermacoccus gen. nov., and Micrococcus Cohn 1872 gen. emend.
}

\author{
ERKO STACKEBRANDT, ${ }^{1 *}$ CATHRIN KOCH, ${ }^{1}$ OXANA GVOZDIAK, ${ }^{2}$ \\ AND PETER SCHUMANN ${ }^{3}$ \\ DSM-German Collection of Microorganisms and Cell Cultures GmbH, 38124 Braunschweig, ${ }^{1}$ \\ and 07708 Jena, ${ }^{3}$ Germany, and Zabolotny Institute of Microbiology and Virology, \\ National Academy of Sciences of Ukraine, Kiev, 252143 Ukraine $^{2}$
}

\begin{abstract}
The results of a phylogenetic and chemotaxonomic analysis of the genus Micrococcus indicated that it is significantly heterogeneous. Except for Micrococcus lylae, no species groups phylogenetically with the type species of the genus, Micrococcus luteus. The other members of the genus form three separate phylogenetic lines which on the basis of chemotaxonomic properties can be assigned to four genera. These genera are the genus Kocuria gen. nov. for Micrococcus roseus, Micrococcus varians, and Micrococcus kristinae, described as Kocuria rosea comb. nov., Kocuria varians comb. nov., and Kocuria kristinae comb. nov., respectively; the genus Nesterenkonia gen. nov. for Micrococcus halobius, described as Nesterenkonia halobia comb. nov.; the genus Kytococcus gen. nov. for Micrococcus nishinomiyaensis, described as Kytococcus nishinomiyaensis comb. nov.; and the genus Dermacoccus gen. nov. for Micrococcus sedentarius, described as Dermacoccus sedentarius comb. nov. M. luteus and $M$. lylae, which are closely related phylogenetically but differ in some chemotaxonomic properties, are the only species that remain in the genus Micrococcus Cohn 1872. An emended description of the genus Micrococcus is given.
\end{abstract}

The genus Micrococcus was first described more than 100 years ago, and since then the description has been revised several times. Today it is clear that this genus, which phenotypically belongs to the broad group of gram-positive, catalasepositive cocci, phylogenetically belongs to the actinomycete group (47). However, the phylogenetically proper place for these bacteria has still not been determined. Stackebrandt and Woese (50) found on the basis of the results of $16 \mathrm{~S}$ rRNA cataloguing that the micrococci appeared to overlap with $\mathrm{Ar}$ throbacter species and that it was impossible by using this method "to construct a reasonable, comprehensive cluster of Micrococcus species that excludes all Arthrobacter species." This observation was based on the results of an analysis of only a few species belonging to each genus. Therefore, the phylogenetic depth and width of these two genera and of the Arthrobacter line of descent within the subphylum of actinomycetes had not been fully explored. Early comparative chemotaxonomic analyses $(9,11-13,34,53)$, a genetic analysis (20), and determinations of levels of DNA-DNA similarity (35, 44) also did not include all of the valid species known today. Although the previous phylogenetic studies included only micrococci, these studies led to the following taxonomic rearrangements: certain radiation-resistant red micrococci were transferred to the genus Deinococcus (2); Micrococcus mucilaginosus was reclassified as Stomatococcus mucilaginosus (1); and Micrococcus agilis was found to be a phylogenetic member of the "Arthrobacter globiformis-Arthrobacter citreus group" (sensu Keddie and Jones [19]), and as this species also had chemotaxonomic properties in common with its nonmicrococ-

* Corresponding author. Mailing address: DSM-German Collection of Microorganisms and Cell Cultures GmbH, Mascheroder Weg 1b, 38124 Braunschweig, Germany. Phone: 00495312616 352. Fax: 0049 5312616 418. Electronic mail address: erko@gbf-braunschweig.de. cal relatives, Koch and Stackebrandt proposed that it should be redescribed as Arthrobacter agilis (24).

The results of a recent analysis of almost complete $16 \mathrm{~S}$ ribosomal DNA (rDNA) sequences of all valid Arthrobacter species (23) and the majority of the Micrococcus species (24) fully supported the previous conclusion about the intermixing of some of the Micrococcus and Arthrobacter species. The existence of two major clusters of Arthrobacter species was demonstrated, and the compositions of these clusters correlated well with chemotaxonomic properties (18). A few Arthrobacter species branched as close phylogenetic neighbors, but their position was not supported by high levels of statistical confidence. As found previously, the type species of the genus Micrococcus (Micrococcus luteus) and its closest relative, Micrococcus lylae, grouped with the type species of the genus Arthrobacter, A. globiformis, and its relatives.

In order to provide a basis for a thorough phylogenetic analysis of the genera Arthrobacter and Micrococcus, the 16S rDNA sequences of the type strains of all Micrococcus species not previously investigated were determined in this study. In addition, we reanalyzed in a single comparative study those chemotaxonomic properties that, together with the amino acid composition of peptidoglycan, have been found to be excellent markers for delimitation of genera in the order Actinomycetales (i.e., fatty acid, polar lipid, and menaquinone compositions).

\section{MATERIALS AND METHODS}

Bacterial strains and cultivation. The following strains were investigated to determine their fatty acid and mycolic acid patterns: Micrococcus halobius DSM $20541^{\mathrm{T}}$ ( $\mathrm{T}=$ type strain), Micrococcus kristinae DSM 20032 ${ }^{\mathrm{T}}$, M. luteus DSM $20030^{\mathrm{T}}, M$. lylae DSM $20315^{\mathrm{T}}$, Micrococcus nishinomiyaensis DSM $20448^{\mathrm{T}}, \mathrm{Mi}$ crococcus roseus DSM $20447^{\mathrm{T}}$, Micrococcus sedentarius DSM $20547^{\mathrm{T}}$, Micrococcus varians DSM $20033^{\mathrm{T}}$, S. mucilaginosus DSM $20746^{\mathrm{T}}$, and Rothia dentocariosa DSM $46363^{\mathrm{T}}$. The $16 \mathrm{~S}$ rDNA analysis was performed by using strains DSM $20448^{\mathrm{T}}$, DSM $20447^{\mathrm{T}}$, DSM $20547^{\mathrm{T}}$, DSM $20033^{\mathrm{T}}$, and DSM $20746^{\mathrm{T}}$. To isolate DNAs, strains were grown on medium 53 at $30^{\circ} \mathrm{C}$ as recommended in the 
TABLE 1 . Dissimilarity matrix based on corrected $16 \mathrm{~S}$ rDNA sequence similarity data ${ }^{a}$

\begin{tabular}{|c|c|c|c|c|c|c|c|c|c|c|c|c|c|c|c|c|c|c|c|c|c|c|c|}
\hline \multirow[b]{2}{*}{ Organism $^{b}$} & \multicolumn{23}{|c|}{ Evolutionary distance } \\
\hline & 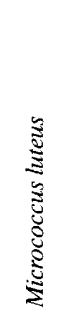 & 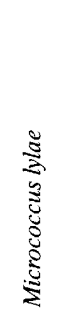 & 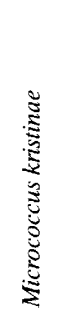 & 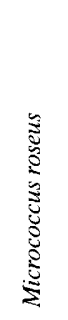 & 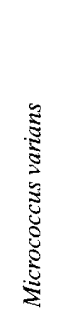 & 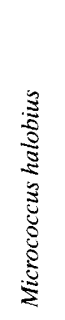 & 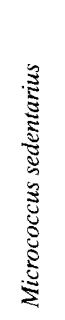 & 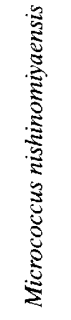 & 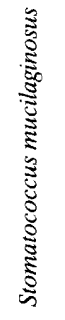 & 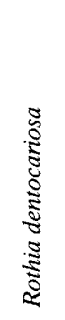 & 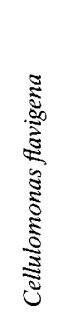 & 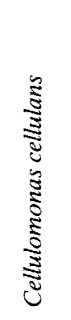 & 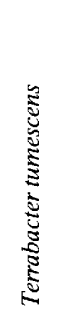 & 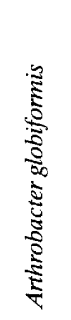 & 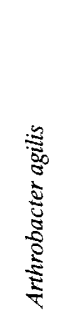 & 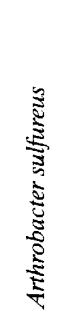 & 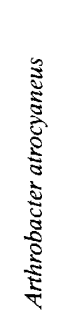 & 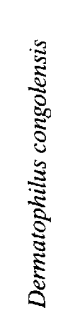 & 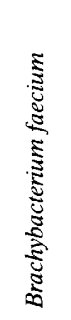 & 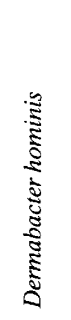 & 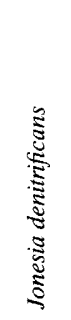 & 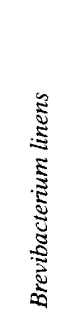 & 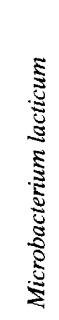 \\
\hline Micrococcus lylae & 1.4 & & & & & & & & & & & & & & & & & & & & & & \\
\hline Micrococcus kristinae & 6.9 & 6.6 & & & & & & & & & & & & & & & & & & & & & \\
\hline Micrococcus roseus & 4.4 & 4.5 & 4.3 & & & & & & & & & & & & & & & & & & & & \\
\hline Micrococcus varians & 6.0 & 6.3 & 3.7 & 3.1 & & & & & & & & & & & & & & & & & & & \\
\hline Micrococcus halobius & 5.9 & 5.7 & 6.1 & 5.4 & 5.6 & & & & & & & & & & & & & & & & & & \\
\hline Micrococcus sedentarius & 6.3 & 6.5 & 7.6 & 6.5 & 6.9 & 7.1 & & & & & & & & & & & & & & & & & \\
\hline Micrococcus nishinomiyaensis & 6.3 & 6.8 & 7.4 & 5.5 & 6.6 & 7.8 & 5.1 & & & & & & & & & & & & & & & & \\
\hline Stomatococcus mucilaginosus & 5.4 & 5.7 & 5.8 & 4.0 & 5.2 & 6.2 & 7.1 & 6.7 & & & & & & & & & & & & & & & \\
\hline Rothia dentocariosa & 5.9 & 6.0 & 5.6 & 4.3 & 5.6 & 6.9 & 7.5 & 6.8 & 2.2 & & & & & & & & & & & & & & \\
\hline Cellulomonas flavigena & 7.9 & 8.2 & 8.2 & 7.9 & 7.9 & 9.0 & 8.0 & 7.6 & 8.6 & 9.0 & & & & & & & & & & & & & \\
\hline Cellulomonas cellulans & 7.0 & 7.5 & 8.0 & 6.9 & 7.7 & 8.3 & 7.0 & 7.2 & 7.5 & 8.2 & 5.9 & & & & & & & & & & & & \\
\hline Terrabacter tumescens & 7.1 & 7.4 & 7.6 & 6.8 & 7.1 & 8.9 & 5.3 & 5.2 & 7.6 & 7.7 & 6.8 & 6.3 & & & & & & & & & & & \\
\hline Arthrobacter globiformis & 3.6 & 3.8 & 5.5 & 3.7 & 4.9 & 5.2 & 6.5 & 6.2 & 5.2 & 5.5 & 8.0 & 7.1 & 7.0 & & & & & & & & & & \\
\hline Arthrobacter agilis & 5.1 & 5.2 & 6.5 & 4.7 & 6.1 & 6.1 & 7.6 & 6.2 & 6.5 & 6.6 & 7.9 & 7.5 & 8.5 & 4.0 & & & & & & & & & \\
\hline Arthrobacter sulfureus & 4.0 & 4.4 & 7.0 & 5.1 & 6.4 & 6.6 & 7.7 & 7.3 & 6.6 & 7.1 & 9.0 & 8.0 & 7.6 & 2.6 & 5.9 & & & & & & & & \\
\hline Arthrobacter atrocyaneus & 5.4 & 5.8 & 6.8 & 4.9 & 6.5 & 7.0 & 8.0 & 7.1 & 7.0 & 7.3 & 8.2 & 7.4 & 8.5 & 5.2 & 5.5 & 6.8 & & & & & & & \\
\hline Dermatophilus congolensis & 7.0 & 7.3 & 8.6 & 6.9 & 7.6 & 8.2 & 6.1 & 5.6 & 7.4 & 8.0 & 7.3 & 7.9 & 6.9 & 6.9 & 7.8 & 8.3 & 9.0 & & & & & & \\
\hline Brachybacterium faecium & 7.0 & 7.2 & 8.1 & 6.5 & 7.1 & 7.5 & 6.8 & 8.0 & 8.0 & 8.7 & 9.0 & 7.4 & 6.5 & 6.2 & 8.0 & 6.8 & 7.7 & 8.0 & & & & & \\
\hline Dermabacter hominis & 6.7 & 7.4 & 7.9 & 7.0 & 7.4 & 6.9 & 7.4 & 7.7 & 8.0 & 8.5 & 8.9 & 7.2 & 7.3 & 6.6 & 8.0 & 6.8 & 8.2 & 7.5 & 5.1 & & & & \\
\hline Jonesia denitrificans & 8.6 & 8.9 & 8.6 & 8.1 & 8.6 & 9.5 & 8.8 & 9.9 & 9.3 & 10.1 & 9.5 & 8.3 & 9.1 & 8.6 & 9.2 & 8.7 & 9.0 & 9.8 & 8.8 & 8.1 & & & \\
\hline Brevibacterium linens & 10.3 & 10.1 & 9.0 & 8.9 & 8.3 & 9.0 & 9.6 & 10.1 & 9.5 & 9.7 & 11.0 & 9.5 & 9.7 & 10.1 & 10.7 & 9.9 & 10.8 & 10.0 & 9.4 & 10.2 & 10.9 & & \\
\hline cticum & 9.0 & 9.0 & 10.5 & 9.0 & 9.4 & 10.6 & 9.7 & 10.7 & 9.8 & 10.6 & 8.6 & 8.8 & 8.6 & 9.5 & 10.6 & 9.2 & 10.2 & 9.8 & 10.6 & 10.9 & 11.7 & 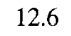 & \\
\hline Nocardioides simplex & 11.8 & 11.9 & 13.9 & 11.8 & 12.9 & 14.2 & 12.4 & 12.3 & 13.0 & 13.1 & 12.0 & 11.1 & 12.4 & 11.8 & 12.6 & 12.5 & 13.0 & 11.9 & 13.6 & 13.6 & 14.7 & 14.8 & \\
\hline
\end{tabular}

${ }^{a}$ Pairwise evolutionary distances were computed by using the correction of Jukes and Cantor (16).

${ }^{b}$ The type strains were used in this analysis.

DSM-Deutsche Sammlung von Mikroorganismen und Zellkulturen GmbH Catalogue of strains (8). For fatty acid, menaquinone, and mycolic acid analyses strains were grown under standardized conditions in tryptic soy broth (8) (fatty acid analysis) or in medium 426 described in the DSM-Deutsche Sammlung von Mikroorganismen und Zellkulturen $\mathrm{GmbH}$ Catalogue of Strains (menaquinone analysis) for 24 hours at $28^{\circ} \mathrm{C}$. For cultivation of $M$. halobius $6 \% \mathrm{NaCl}$ was added to the medium.

Analysis of cellular fatty acids. Cellular fatty acid methyl esters were obtained by the method described by Stead et al. (51) and were separated by gas chromatography on a type OV- 1 capillary column $(25 \mathrm{~m}$ by $0.25 \mathrm{~mm}$ [inside diameter]) by using $\mathrm{He}$ at a linear velocity of $200 \mathrm{~mm} / \mathrm{s}$ at $190^{\circ} \mathrm{C}$. The gas chromatographic analyses were performed by using a model GC-14A gas chromatograph fitted with a flame ionization detector and a model C-R4AX Chromatopac integrator (Shimadzu Corp., Tokyo, Japan).

Analysis of isoprenoid quinones. Menaquinones were extracted as described by Collins et al. (6) and were analyzed by high-performance liquid chromatography (HPLC). The menaquinones were eluted from a type RP 18 column ( 250 by $4.6 \mathrm{~mm}$ [inside diameter]) by using acetonitrile-2-propanol $(65: 35, \mathrm{vol} / \mathrm{vol})$ at a flow rate of $1.3 \mathrm{ml} / \mathrm{min}$ at $30^{\circ} \mathrm{C}$. The detection wavelength was $269 \mathrm{~nm}$. The HPLC system used consisted of a model LC-9A solvent delivery module, a model DGU-3A online degasser, a model CTO-10AC column oven, a model SIL-9A automatic sample injector, and a model SPD-6A UV spectrophotometric detector connected to the model C-R4AX integrator (Shimadzu Corp.).

Analysis of polar lipids and mycolic acids. Polar lipids extracted by the method of Minnikin et al. (33) were identified by two-dimensional thin-layer chromatography and were sprayed with specific reagents as described by Collins and Jones (4). The presence of mycolic acids was investigated as described previously (33).

16S rDNA sequencing. The methods used to extract genomic DNA and amplify the 16S rDNA have been described previously (37). PCR products were sequenced directly by using a Taq DyeDeoxy Terminator Cycle Sequencing Kit (Applied Biosystems, Foster City, Calif.) and the manufacturer's protocol. The sequence reaction mixtures were electrophoresed by using an Applied Biosystems model 373A DNA sequencer.

Phylogenetic analysis. The new sequences which we obtained were manually aligned with sequences published previously for members of the genera Agro- myces, Aureobacterium, Curtobacterium, Clavibacter, and Rathayibacter (38), the genera Arthrobacter and Micrococcus $(23,24)$, the genera Brevibacterium, Cellulomonas, Oerskovia, Promicromonospora, and Jonesia (39), the genus Brachybacterium (3), and the genera Dermabacter, Dermatophilus, Renibacterium, Rothia, and Terrabacter (31). Dissimilarity values were transformed into phylogenetic distance values that compensated for multiple substitutions at any given site in the sequence (16). Phylogenetic trees were reconstructed from the corrected dissimilarity values by using distance matrix methods based on the algorithms of Saitou and Nei (42) and De Soete (7). Neighbor-joining, maximum-likelihood, and maximum-parsimony analyses were performed by using the programs com: piled in the Phylogeny Inference Package (10). A bootstrap analysis was performed by using the programs NJFIND and NJBOOT.

Nucleotide sequence accession numbers. The $16 \mathrm{~S}$ rDNA sequences of $M$. nishinomiyaensis, $M$. roseus, $M$. sedentarius, $M$. varians, and $S$. mucilaginosus have been deposited in the EMBL data library under accession numbers X87757, $\mathrm{X} 87756, \mathrm{X} 87755, \mathrm{X} 87754$, and $\mathrm{X} 87758$, respectively.

\section{RESULTS}

Phylogenetic analysis. Almost complete 16S rDNA sequences were determined for the type strains of $M$. kristinae, $M$. nishinomiyaensis, $M$. roseus, $M$. sedentarius, and $M$. varians. In addition, the sequence of $S$. mucilaginosus was analyzed because the results of a previous phylogenetic study indicated that this taxon may be related to members of the genus Micrococcus (49) on the basis of the presence of L-lysine in the peptidoglycan (45) and morphology. The sequences were aligned with the $16 \mathrm{~S}$ rDNA database sequences of 51 members of the Arthrobacter subline of descent. A subset of 40 type strains was used to generate a matrix of dissimilarity values; some of these values are shown in Table 1. 


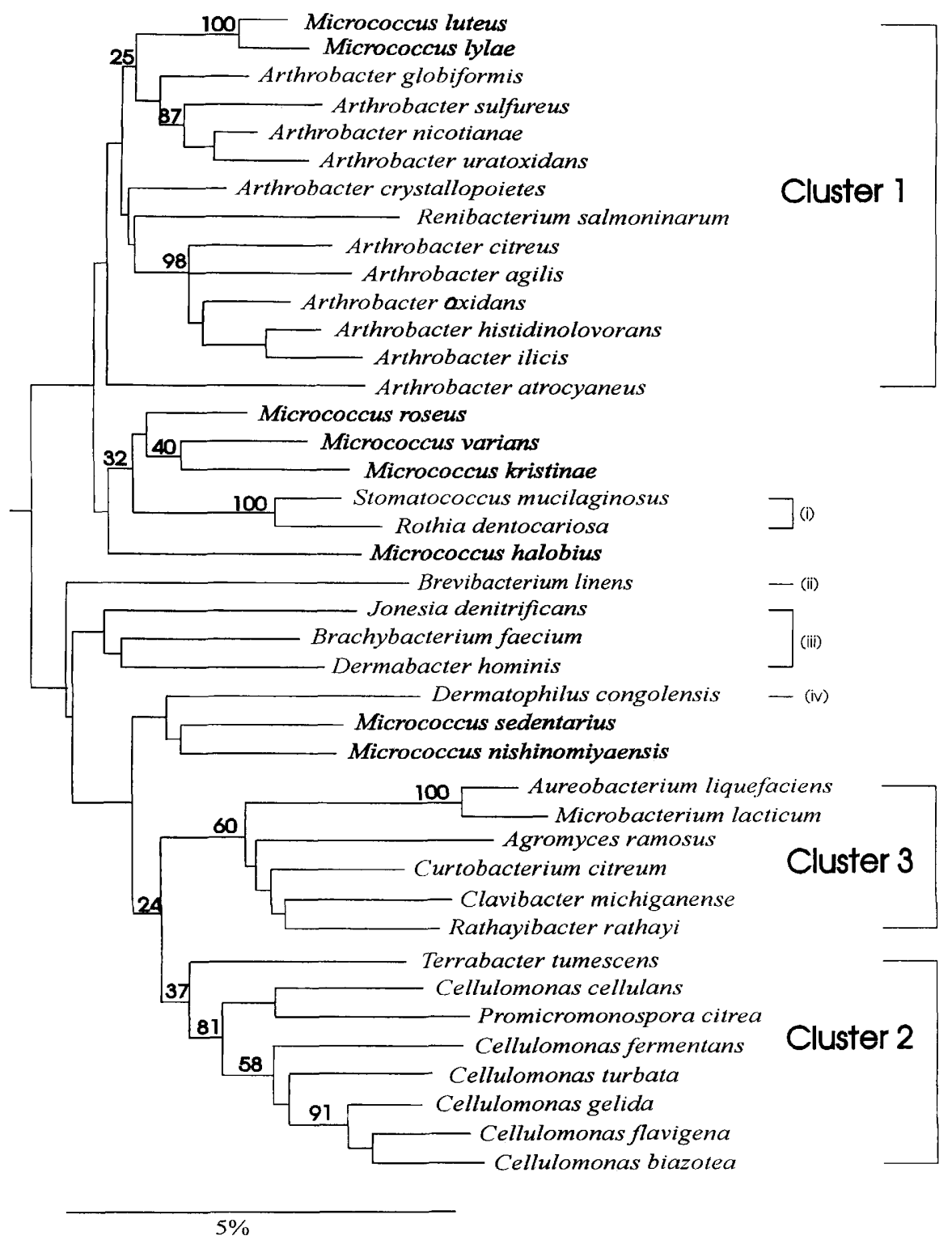

FIG. 1. Distance matrix tree (7), showing the phylogenetic positions of Micrococcus species within the Arthrobacter lineage of the subphylum of Actinomycetales. Nocardioides simplex was used as the root. The corrected dissimilarity values for selected representatives of the genera are shown in Table 1. Values for the other reference organisms have been published previously $(23,24,38,39)$. The numbers indicate the percentages of occurrence in 300 bootstrapped trees; only values greater than $20 \%$ are shown. Bar $=5$ nucleotide substitutions per 100 nucleotides.

All of the algorithms used in this study resulted in the following conclusion with respect to the phylogenetic position of Micrococcus species: the Micrococcus species do not cluster together but form four separate sublines and the composition of Micrococcus species in each of these sublines is constant. However, bootstrap values less than $50 \%$ indicated that the order of most of the deeper branches and the order of most of the species-rich lines within the Arthrobacter lineage have no statistical significance (Fig. 1). Nevertheless, the branching points of the four sublines are almost identical in the trees derived from distance matrix data $(7,10,42)$. The $16 \mathrm{~S}$ rDNA dendrogram obtained by the method of De Soete (7) (Fig. 1) is representative of the phylogenetic patterns obtained. Some deviations were detected in the dendrogram obtained when the maximum-parsimony analysis method was used; these deviations were found especially with remotely related organisms, such as $M$. halobius and Jonesia denitrificans, and in the formation of two separate phylogenetic lines for the Rothia-Stomatococcus genus pair and the species $M$. roseus, $M$. varians, and $M$. kristinae (data not shown).

When Nocardioides simplex was used as the root, the $A r$ throbacter lineage contained several main clusters, three of which were species rich (Fig. 1); one of these clusters contained Arthrobacter and Renibacterium species, a second cluster contained the genera Cellulomonas, Oerskovia, Promicromonospora, and Terrabacter, and the third group contained organisms with group B peptidoglycan, as classified by Schleifer and Kandler (45). The following four lineages containing only a few taxa were also detected (Fig. 1): (i) a lineage containing members of the genera Stomatococcus and Rothia, (ii) a lineage containing Brevibacterium species, (iii) a lineage containing members of the genera Brachybacterium, Dermato- 
TABLE 2. Menaquinone compositions and peptidoglycan types of type strains of species belonging to the genera Micrococcus, Stomatococcus, and Rothia and of $A$. globiformis and $A$. nicotianae strains

\begin{tabular}{|c|c|c|c|c|c|c|c|c|c|c|}
\hline \multirow{2}{*}{ Organism } & \multicolumn{9}{|c|}{ Menaquinone composition ${ }^{a}$} & \multirow{2}{*}{ Peptidoglycan type $\mathrm{e}^{b}$} \\
\hline & MK-6 & MK-7 & MK-8 & MK-9 & MK-10 & MK-11 & $\mathrm{MK}-7\left(\mathrm{H}_{2}\right)$ & MK- $8\left(\mathbf{H}_{2}\right)$ & MK-9 $\left(\mathrm{H}_{2}\right)$ & \\
\hline$M$. luteus & & $+^{c}$ & +++ & & & & & $+t$ & & L-Lys-peptide subunit \\
\hline M. lylae & & & & & & & + & +++ & + & LLys-D-Asp \\
\hline A. globiformis & & & & + & & & + & + & +++ & L-Lys-L-Ala 3 \\
\hline A. nicotianae & & + & +++ & + & & & & & & L-Lys-L-Ala-D-Glu \\
\hline M. varians & & & & & & & +++ & + & & LLys-L-Ala ${ }_{3-4}$ \\
\hline M. kristinae & & & & & & & +++ & ++ & & L-Lys-L-Ala $3-4$ \\
\hline M. roseus & & & & & & & + & +++ & + & L-Lys-L-Ala $3-4$ \\
\hline M. halobius & & + & +++ & ++ & & & & & & L-Lys-Gly-L-Glu \\
\hline M. nishinomiyaensis & & & & & & & + & +++ & + & L-Lys-L-Ser ${ }_{1-2}-$ (L-Ala)-D-Glu \\
\hline M. sedentarius & & & +++ & ++ & ++ & + & & & & L-Lys-D-Glu 2 \\
\hline S. mucilaginosus & + & +++ & + & & & & & & & L-Lys-L-Ala \\
\hline Rothia dentocariosa & + & $+t+$ & + & & & & & & & L-Lys-L-Ala \\
\hline
\end{tabular}

${ }^{a}$ The menaquinone composition data for the Arthrobacter strains were obtained from reference 5 .

${ }^{b}$ Data from references 8 and 45 .

${ }^{c}+,<10 \% ;++, 10$ to $50 \% ;+++,>50 \%$.

bacter, and Jonesia, and (iv) a lineage containing Dermatophilus congolensis.

The eight Micrococcus species occur in four separate positions on the tree. Most obvious is the branching of the type species of the genus Micrococcus, $M$. luteus, and its closest relative, $M$. lylae, in the phylogenetic neighborhood of the type species of the genus Arthrobacter, A. globiformis, and its relatives (23). This group also contains $A$. agilis, which has recently been transferred from the genus Micrococcus (24), as well as Renibacterium salmoninarum. A second Micrococcus group consists of $M$. kristinae, $M$. varians, and $M$. roseus; these species cluster next to the species pair $S$. mucilaginosus and Rothia dentocariosa. A third group is defined by the single species $M$. halobius, while the remotely related species pair $M$. sedentarius and $M$. nishinomiyaensis appear to be the most distantly related Micrococcus species.

Previous studies on chemotaxonomic properties of the micrococci have revealed similar heterogeneity. However, previously determined data are not available for all validly described species. In the light of the desirability of a polyphasic approach in bacterial systematics, we felt that it was necessary to compare the internal genus structure derived from the 16S rDNA sequence analysis with data from chemotaxonomic studies. Except for peptidoglycan composition, we reanalyzed and determined the chemotaxonomic properties which have been valuable previously in the taxonomy of this group of bacteria. Our results are shown in Tables 2 and 3; Table 2 also contains previously published data on the amino acid compositions of peptidoglycans.

Menaquinone composition. The eight Micrococcus species exhibited four different menaquinone patterns (Table 2). $M$. luteus possesses a fully unsaturated menaquinone with eight isoprene units as the major component and a fully unsaturated menaquinone with seven isoprene units as a minor component. In addition, it also contains substantial amounts $(30 \%)$ of a dihydrogenated menaquinone with eight isoprene units. The phylogenetically closest relative of $M$. luteus, $M$. lylae, contains dihydrogenated menaquinones with seven, eight, and nine iso- prene units, and MK- $8\left(\mathrm{H}_{2}\right)$ is the major menaquinone. Similar patterns were also found for the type strains of $M$. varians, $M$. kristinae, $M$. roseus, and $M$. nishinomiyaensis, although the major component differed among these strains. The third pattern was found for the type strain of $M$. halobius; this species contains fully unsaturated menaquinones with seven and nine isoprene units, but predominant menaquinone is a fully unsaturated menaquinone with eight isoprene units. $M$. sedentarius represents the fourth type; this species contains fully unsaturated menaquinones with between 8 and 11 isoprene units.

Our analysis of the type strains of $S$. mucilaginosus and Rothia dentocariosa revealed very similar patterns that were not found in any of the type strains of Micrococcus species. Both of these taxa contain fully unsaturated menaquinones with six, seven, and eight isoprene units, and MK-7 is the major component.

Fatty acid composition. Only some of the groups defined by menaquinone composition data could be identified on the basis of the fatty acid analysis results (Table 3). M. luteus and $M$. lylae are similar in that they contain major amounts of iso and anteiso methyl-branched-chain acids, including 13-methyltetradecanoic acid (iso- $\mathrm{C}_{15: 0}$ ) and 12-methyltetradecanoic acid (anteiso- $C_{15: 0}$ ). A similar composition, although with a lower amount of iso- $\mathrm{C}_{15.0}$, has been found for the type strains of the two Arthrobacter species that represent the two recognized intrageneric clusters, $A$. globiformis and Arthrobacter nicotianae (18).

The members of the cluster containing $M$. varians, $M$. roseus, and $M$. kristinae have major amounts of 12 -methyltetradecanoic acid (anteiso- $\mathrm{C}_{15: 0}$ ) and strain-dependent smaller amounts of other fatty acids, including 14-methylpentadecanoic acid (iso- $\left.\mathrm{C}_{16: 0}\right)$ (M. varians, $M$. kristinae), hexadecanoic acid $\left(\mathrm{C}_{16: 0}\right)$ (M. varians), 14-methylhexadecanoic acid (anteiso$\left.\mathrm{C}_{17: 0}\right)(M$. varians, $M$. kristinae), 13-methyltetradecanoic acid (iso- $\left.\mathrm{C}_{15: 0}\right)\left(M\right.$. roseus), and hexadecenoic acid $\left(\mathrm{C}_{16: 1}\right)$ (M. roseus). A similar composition is found in $M$. halobius, in which anteiso- $\mathrm{C}_{17: 0}$ is present at a higher level $(22.6 \%)$ than in the 


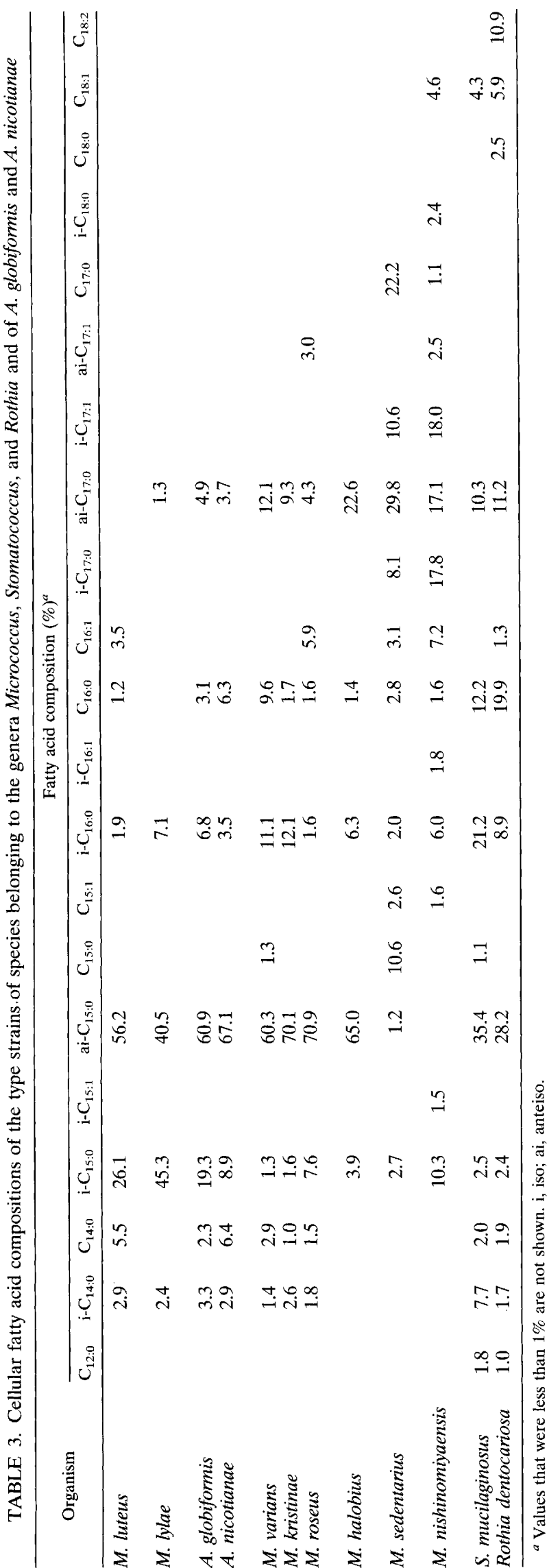

type strains of $M$. varians, $M$. roseus, and $M$. kristinae (4.3 to $12.1 \%$ ).

$M$. sedentarius contains several fatty acids that are not found in other Micrococcus species, such as the saturated acids pentadecanoic acid $\left(\mathrm{C}_{15: 0}\right)$ and heptadecanoic acid $\left(\mathrm{C}_{17: 0}\right)$ and the branched acid 15-methylhexadecanoic acid (iso- $\mathrm{C}_{17: 0}$ ). In addition, significant amounts of 15 -methylhexadecenoic acid (iso$\mathrm{C}_{17: 1}$ ) and 14-methylhexadecanoic acid (anteiso- $\mathrm{C}_{17: 0}$ ) are present.

M. nishinomiyaensis contains predominantly branched acids, such as 13-methyltetradecanoic acid (iso- $\mathrm{C}_{15: 0}$ ), 15-methylhexadecanoic acid (iso- $\mathrm{C}_{17: 0}$ ), 15-methylhexadecenoic acid (iso- $\mathrm{C}_{17: 1}$ ), and 14-methylhexadecanoic acid (anteiso- $\mathrm{C}_{17: 0}$ ), in addition to smaller amounts of hexadecenoic acid $\left(\mathrm{C}_{16: 1}\right)$ and 14-methylpentadecanoic acid (iso- $\mathrm{C}_{16: 0}$ ).

The fatty acid compositions of $S$. mucilaginosus and Rothia dentocariosa are similar in that they include a broad range of fatty acids from $C_{12: 0}$ to $C_{18: 2}$. These organisms differ from each other in that the former species contains high levels of 14-methylpentadecanoic acid (iso- $\mathrm{C}_{16: 0}$ ), while the latter species contains octadecadienoic acid $\left(\mathrm{C}_{18: 2}\right)$.

The fatty acid composition of the type strain of $S$. mucilaginosus is very similar to the fatty acid compositions determined for several strains of this species (12). Therefore, we believe that the compositions that have been determined for the type strains of Micrococcus species are representative of the species. However, we are aware that qualitative and quantitative fatty acid compositions depend to some extent on the growth medium and the growth stage and that small differences in published data can be explained by these extrinsic factors.

Polar lipids. The polar lipids of the strains investigated in this study are basically the same as the polar lipids found in other members of the Arthrobacter line of descent, in addition to unknown phospholipids and glycolipids. However, phosphatidylinositol mannosides were absent in all of the organisms which we investigated. Also, phosphatidylinositol was not present in some strains, although this phospholipid is usually present in members of the order Actinomycetales (32). Several strains contained unknown ninhydrin-negative phospholipids and/or glycolipids.

The same composition was found in $M$. luteus, $M$. halobius, and $M$. kristinae; these organisms contain phosphatidylglycerol, diphosphatidylglycerol, phosphatidylinositol, and the unknown lipids. A similar pattern but without phosphatidylinositol was found in $M$. lylae and $S$. mucilaginosus. $M$. sedentarius and $M$. nishinomiyaensis had the same pattern, as did $M$. varians and $M$. roseus. Rothia dentocariosa had a unique pattern.

Peptidoglycan composition. The amino acid compositions of the peptidoglycans of several Micrococcus species (Table 2) have been published previously by Schleifer and Kandler (45), while other peptidoglycan amino acid compositions have been described by Kocur (25) and in the DSM-Deutsche Sammlung von Mikroorganismen und Zellkulturen $\mathrm{GmbH}$ Catalogue of strains (8). All of the strains possess group A peptidoglycan (cross-linkage from the dicarboxylic acid at position 3 of the peptide subunit, which is L-Lys). However, the amino acid compositions of the interpeptide subunits differ significantly. While $M$. luteus exhibits the most unusual composition because the interpeptide bridge has the same composition as the peptide subunit (variation A2), strains of $M$. roseus, $M$. kristinae, and $M$. varians contain either several monocarboxylic acids (alanine; variation $\mathrm{A} 3 \alpha$ ), strains of $M$. lylae and $M$. sedentarius contain one dicarboxylic amino acid (aspartic acid and glutamic acid moities, respectively; variation $\mathrm{A} 4 \alpha$ ), and $M$. nishinomiyaensis and $M$. halobius strains contain a monocarboxylic 
acid and a dicarboxylic acid (serine and glutamic acid and glycine and glutamic acid, respectively; variation $\mathrm{A} 4 \alpha$ ).

\section{DISCUSSION}

The close relationship between Micrococcus and $\mathrm{Ar}$ throbacter species was noted before results of $16 \mathrm{~S}$ rDNA sequence analyses became available. In 1974 Keddie (17) pointed out that "Micrococcus species should be regarded as degenerate forms, locked into the coccoid stage of the $A r$ throbacter life cycle. These molecular data suggest that micrococci should be accommodated in one family with the genus Arthrobacter" (25). What could not be determined at that time, however, was the placement of the Micrococcus species in relation to their phylogenetic neighbors and whether the genus Micrococcus is a phylogenetically coherent genus.

Early DNA-DNA hybridization experiments performed with the type strains of $M$. luteus, $M$. varians, and $M$. roseus revealed complementarity values of less than $10 \%$ (35). These results were confirmed by Schleifer et al. (44), who also included the type strains of $M$. lylae and $M$. kristinae in their study. While the DNAs of $M$. lylae and $M$. luteus exhibited a moderate level of similarity $(44 \%)$ under optimal hybridization conditions, $M$. kristinae was as unrelated to $M$. luteus as the type strain of $M$. varians was. The close relationship between $M$. luteus and $M$. lylae and the lack of a relationship between these species and the other members of the genus Micrococcus were also revealed by other methods. The rates of transformation of an auxotrophic strain of $M$. luteus with strains of $M$. lylae were significantly higher ( 1 to $12 \%$ of the homologous transformation rate) than the transformation rates observed with DNAs from other Micrococcus strains. The values ranged from 0.1 to $0.8 \%$ for strains of $M$. sedentarius to no transformation when DNAs originating from $M$. varians, $M$. roseus, $M$. kristinae, and $M$. nishinomiyaensis were used (20). Similar results were obtained in a comparative immunological study of catalase activity (41). Double immunodiffusion tests were performed by using antisera against $M$. luteus catalase and crude extracts of strains of all Micrococcus species except M. halobius. While the cell extract of $M$. lylae reacted strongly, weak reactions or no reactions at all were observed with extracts from members of the other species. A similar picture was obtained when immunological distances were calculated; this study revealed that the distance between $M$. luteus and the other micrococci (except $M$. lylae) was as great as the distances between M. luteus and members of distantly related genera (41). The relatedness of $M$. luteus and $M$. lylae was also demonstrated by using an oligonucleotide probe directed against the 23S rDNA of $M$. luteus. Only the DNA of $M$. lylae gave a positive hybridization signal, whereas the DNAs of the four other Micrococcus species studied were negative in this analysis (40).

When DNA hybridization, transformation, and immunology studies were performed, there was no indication that the genus Micrococcus might be phylogenetically heterogeneous. Therefore, it is not surprising that members of other genera were not included in these studies, which, at an early stage, might have pointed toward the phylogenetic heterogeneity of the genus Micrococcus. Even the first 16S rRNA cataloguing data did not convincingly demonstrate the taxonomic incoherence of the genus Micrococcus.

The results of this study, in which we included representatives of all previously described species of the genera Micrococcus, Arthrobacter, Stomatococcus, Renibacterium, Rothia, Cellulomonas, and Oerskovia, as well as the genera whose members contain group B peptidoglycan (not all data are shown), demonstrate the full degree of diversity among the
Micrococcus species. The levels of unrelatedness, as determined by $16 \mathrm{~S}$ rDNA analysis, were fully supported by the results of chemotaxonomic property analyses, which have been found to be extremely useful for delimitating genera within the order Actinomycetales. A combination of these properties not only permitted separation of five groups of phylogenetically well-defined clusters of micrococci but also unambiguously separated these clusters, especially in combination with spherical morphology, from phylogenetically related neighboring taxa (Table 4); hence, a combination of properties allowed us to assign novel taxa to these clusters.

As the distinct phylogenetic positions of most Micrococcus species correlate convincingly with distinct chemotaxonomic character patterns, we propose descriptions of several new genera below. We propose that $M$. kristinae, $M$. roseus, and $M$. varians should be classified as species of the genus Kocuria gen. nov. as Kocuria kristinae comb. nov., Kocuria rosea comb. nov., and Kocuria varians comb. nov., respectively; that M. halobius should be classified as a species of the genus Nesterenkonia gen. nov. as Nesterenkonia halobia comb. nov.; that $M$. sedentarius should be classified as a species of the genus Kytococcus gen. nov. as Kytococcus sedentarius comb. nov.; and that $M$. nishinomiyaensis should be classified as a species of the genus Dermacoccus gen. nov. as Dermacoccus nishinomiyaensis comb. nov.

As pointed out above, the level of relatedness between $M$. luteus and $M$. lylae is significantly higher than the levels of relatedness among the other Micrococcus species and the levels of relatedness among the majority of the neighboring $A r$ throbacter species $(23,24)$. Despite this remarkable level of relatedness, $M$. luteus and $M$. lylae differ significantly in chemotaxonomic properties which, as demonstrated here, are suitable for separating genera from each other. Nevertheless, because of the high level of genomic relatedness between these two species, we refrain at this point from describing a novel genus for $M$. lylae. Certainly, our restructuring of the genus Micrococcus is only the beginning of a more extensive reclassification of the genera belonging to the Arthrobacter subline, which includes the genera Arthrobacter and Cellulomonas and the genera with group B peptidoglycan.

Description of the genus Kytococcus. Kytococcus (Ky.to. coc'cus. Gr. neut. n. kytos, skin; Gr. masc. n. kokkos, a grain; M.L. masc. n. Kytococcus, a coccus from skin). The description of the genus Kytococcus below is based on data from references $9,22,25,26,43 a, 45$, and 46, and this study. Cells are coccoid. Gram positive. Nonencapsulated. Endospores are not formed. Nonmotile. Chemoorganotrophic; metabolism is strictly respiratory. Aerobic. Catalase positive. Nonhalophilic. Mesophilic. The peptidoglycan type is type L-Lys-Glu ${ }_{2}$, variation A4 $\alpha$. Mycolic acids and teichoic acids are absent. Menaquinones with 8 , 9 , and 10 completely unsaturated isoprene units (MK-8, MK-9, and MK-10) predominate. The major cellular fatty acids are iso- $\mathrm{C}_{17: 1}$, anteiso- $\mathrm{C}_{17: 0}$, and the straight-chain saturated acids $\mathrm{C}_{15: 0}$ and $\mathrm{C}_{17: 0}$. The cytochromes are cytochromes $a a_{3}, c_{626}$, $c_{550}, b_{557}, b_{561}$, and $b_{564}$. The polar lipids are diphosphatidylglycerol, phosphatidylglycerol, and phosphatidylinositol. The major aliphatic hydrocarbons (br- $\Delta-\mathrm{C}$ ) are $C_{30}$ to $C_{33}$ hydrocarbons.

The $\mathrm{G}+\mathrm{C}$ content of the DNA is 68 to $69 \mathrm{~mol} \%$ (as determined by the thermal denaturation $\left[T_{m}\right]$ method). The type species is Kytococcus sedentarius.

Description of Kytococcus sedentarius (ZoBell and Upham 1944) comb. nov. (Approved Lists 1980). Kytococcus sedentarius (se.den.ta'r.ius. L. v. sedere, to sit; L. adj. sedentarius, sitting). In addition to the properties given above in the genus description, the following properties are characteristic for this 


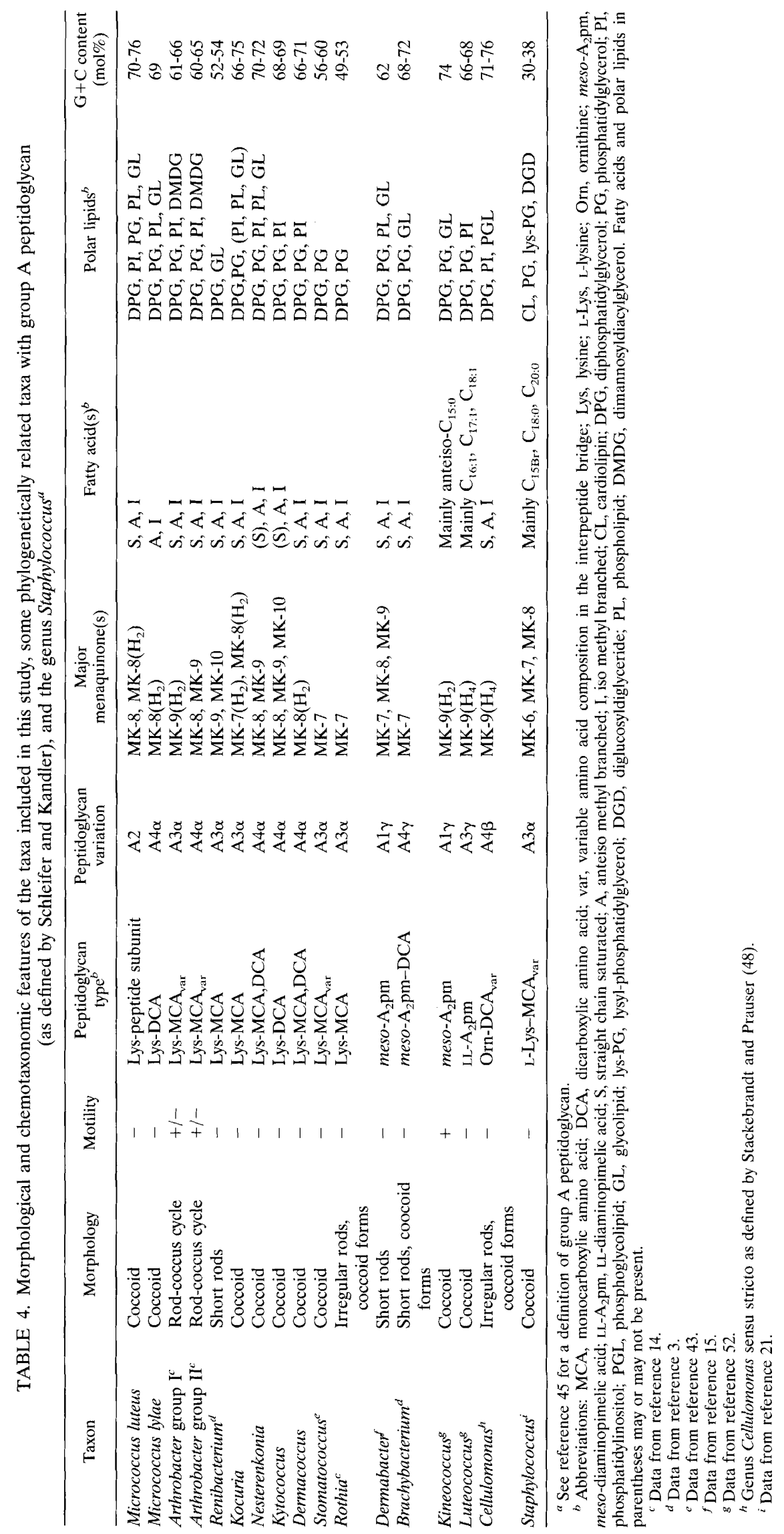


species. Cells are spherical (diameter, 0.8 to $1.1 \mu \mathrm{m}$ ) and occur predominantly in tetrads or in tetrads in cubical packets. In smears cells are often surrounded by a slimy gram-negative layer. Colonies are up to $3.5 \mathrm{~mm}$ in diameter, circular, entire, convex to pulvinate, and usually smooth and develop rather slowly. The colonies are cream white or deep buttercup yellow. Colony morphology and color become more distinct with age; cell morphology is not culture age or medium dependent. Some strains produce a brownish exopigment. Grows well in the presence of $\mathrm{NaCl}$ concentrations up to $10 \%$. Growth does not occur on inorganic nitrogen agar and Simmons citrate agar. Positive in the benzidine test. Most strains are negative in the oxidase test. Arginine dihydrolase positive. Urease, lecithinase, $\beta$-galactosidase, and phosphatase negative. A few strains can reduce nitrate to nitrite; nitrite reduction does not occur. Hydrolyzes gelatin, but does not hydrolyze esculin, starch, and Tween 80 . Acetoin is not produced. Metabolically inert for acid production from carbohydrates. No acid is produced from glucose, galactose, rhamnose, xylose, mannose, maltose, sucrose, ribose, raffinose, melibiose, arabinose, galactose, ribitol, glucitol, galactitol, mannitol, and glycerol. Most strains do not utilize fructose and lactose. Methionine is required. Most strains require tyrosine, arginine, valine, lysine, leucine, and pantothenic acid. The optimum growth temperature range is 28 to $36^{\circ} \mathrm{C}$. Nonhemolytic. All strains are resistant to methicillin and penicillin $\mathrm{G}$ and susceptible to streptomycin, novobiocin, tetracycline, neomycin, vancomycin, and polymyxin $\mathrm{B}$. Most strains are susceptible to erythromycin, kanamycin, and chloramphenicol. The type strain is DSM 20547 ( $=$ ATCC $14392=$ CCM 314).

Description of the genus Nesterenkonia. Nesterenkonia (Ne. ste.ren.ko'ni.a. L. fem. n. Nesterenkonia, honoring Olga Nesterenko, a Ukrainian microbiologist). The description of Nesterenkonia below is based on data from references $25,26,36,45$, and 46 and this study. Cells are coccoid. Gram positive. Nonencapsulated. Endospores are not formed. Chemoorganotrophic; metabolism is strictly respiratory. Aerobic. Catalase positive. Moderately halophilic. Mesophilic. The peptidoglycan type is type L-Lys-Gly-Glu, variation A4 $\alpha$. Mycolic acids are absent. Menaquinones with eight and nine completely unsaturated isoprene units (MK-8 and MK-9) predominate. The phospholipids are diphosphatidylglycerol, phosphatidylglycerol, and phosphatidylinositol. The cellular fatty acids are isoand anteiso-branched fatty acids, with anteiso- $\mathrm{C}_{15: 0}$ and anteiso- $\mathrm{C}_{17: 0}$ predominating. The $\mathrm{G}+\mathrm{C}$ content of the DNA is 70 to $72 \mathrm{~mol} \%$. The type species is Nesterenkonia halobia.

Description of Nesterenkonia halobia (Onishi and Kamekura 1973) comb. nov. (Approved Lists 1980). Nesterenkonia halobia (ha.lo'bi.a. Gr. masc. n. hals, salt; Gr. masc. n. bios, life; M.L. masc. adj. halobia, living on salt). In addition to the characteristics given in the genus description above, this species has the following properties. Spheres (diameter, 0.8 to $1.5 \mu \mathrm{m}$ ) occur singly, in pairs, and sometimes in tetrads or irregular clusters. Colonies on nutrient agar supplemented with $5 \% \mathrm{NaCl}$ are circular, smooth, opaque, and nonpigmented. During growth in nutrient broth, the medium is turbid. Moderately halophilic. Optimum growth occurs on media containing 1 to $2 \mathrm{M} \mathrm{NaCl}$, moderate growth occurs in the presence of $4 \mathrm{M} \mathrm{NaCl}$, and no growth occurs on media lacking $\mathrm{NaCl}$ or $\mathrm{KCl}$. Oxidase test positive. Urease, phosphatase, nitrate reductase, and arginine dihydrolase negative. Does not grow on Simmons citrate agar. Starch is hydrolyzed, while gelatin and Tween 80 are not hydrolyzed. Acetoin production positive and indole and hydrogen sulfide negative. Acid is produced aerobically from glucose, maltose, sucrose, galactose (slowly), xylose, lactose, raffinose, glycerol, mannitol, and starch. No acid is formed from mannose, trehalose, and insulin. Milk coagulation occurs without acid formation. The growth temperature ranges from 20 to $40^{\circ} \mathrm{C}$. Optimum growth occurs at $\mathrm{pH} 7.0$, but strains grow well at $\mathrm{pH} 6$ to 10 . Resistant to lysozyme. Thiamine is required for growth; growth is stimulated by biotin. Nonhemolytic. The type strain is DSM 20541 (= ATCC $21727=$ CCM 2591).

Description of the genus Dermacoccus gen. nov. Dermacoccus (Der.ma.coc'cus. N.L. n. derma, skin: Gr. n. coccus, a grain, berry: M.L. masc. n. Dermacoccus, coccus living on skin). The description of the genus Dermacoccus below is based on data from references $9,25,26,30,43 a, 45$, and 46 and this study. Cells are coccoid. Gram positive. Nonencapsulated. Endospores are not formed. Chemoorganotrophic; metabolism is strictly respiratory. Aerobic; rarely weak growth occurs under microaerophilic conditions. Catalase positive. Nonhalophilic. Mesophilic. The peptidoglycan type is type L-Lys-L-Ser ${ }_{1-2}-\mathrm{D}-$ Glu or L-Lys-L-Ser ${ }_{1-2}-\mathrm{L}-\mathrm{Ala}-\mathrm{D}-\mathrm{Glu}$, variation A4 $\alpha$. Mycolic acids and teichoic acids are absent. Galactosamine is the major constituent of cell wall polysaccharide. The menaquinones are hydrogenated; the predominant menaquinone is $\mathrm{MK}-8\left(\mathrm{H}_{2}\right)$. The cytochromes are cytochromes $a a_{3}, c_{549}, c_{555}, b_{559}, b_{564}$, and $d_{626}$. The polar lipids include diphosphatidylglycerol, phosphatidylglycerol, and phosphatidylinositol. The major fatty acids are iso- $\mathrm{C}_{15: 0}$, iso- $\mathrm{C}_{17: 0}$, iso- and anteiso- $\mathrm{C}_{17: 0}$, and iso- $\mathrm{C}_{17: 1}$. If present, the long-chain aliphatic hydrocarbons (br- $\Delta-\mathrm{C})$ are $\mathrm{C}_{22}$ and $\mathrm{C}_{23}$ hydrocarbons, as well as minor amounts of $\mathrm{C}_{25}$, $\mathrm{C}_{26}$, and $\mathrm{C}_{27}$ hydrocarbons. The $\mathrm{G}+\mathrm{C}$ content of the DNA ranges from 66 to $71 \mathrm{~mol} \%$ (as determined by the $T_{m}$ method). The type species is Dermacoccus nishinomiyaensis.

Description of Dermacoccus nishinomiyaensis (Oda 1935) comb. nov. (Approved Lists 1980). Dermacoccus nishinomiyaensis (ni.shi.no.mi.ya.en'sis. M.L. adj. nishinomiyaensis, pertaining to Nishinomiya, a city in Japan). In addition to the properties given in the genus description above, this species has the following properties. Cells are spherical (diameter, 0.9 to $1.6 \mu \mathrm{m}$ ) and occur in pairs, tetrads, or irregular clusters of tetrads. Colonies are up to $2 \mathrm{~mm}$ in diameter, circular, entire, slightly convex, smooth with glistening (rarely matt) surfaces, and bright orange. Colony morphology and color become more distinct with age; cell morphology is not culture age or medium dependent. Some strains produce a water-soluble orange exopigment. Slight turbidity and a deposit occur during growth in nutrient broth. The final $\mathrm{pH}$ in glucose broth is 5.4 to 6.9 . Growth is weak or absent on inorganic nitrogen agar, and growth does not occur on Simmons citrate agar. Oxidase and benzidine test positive. Negative for free or bound coagulase, phosphatase, lecithinase, arginine dihydrolase, ornithine and lysine decarboxylases, phenylalanine deaminase, $\beta$-galactosidase, and DNase. Most strains produce urease. Gelatin is hydrolyzed, but esculin is not hydrolyzed. Hydrolysis of starch and Tween 80 is variable. Acetoin, indole, and hydrogen sulfide are not produced. Does not utilize sucrose, lactose, galactose, rhamnose, xylose, glycerol, and mannitol. Most strains do not utilize fructose and mannose. Utilization of glucose and galactose is variable. Reduction of nitrate to nitrite is variable; nitrite reduction negative. Methyl red test negative. Cysteine or methionine and niacin are required. Growth is stimulated by tryptophan, valine, aspartic acid, glutamic acid, proline, and lysine. Susceptible to novobiocin and neomycin. Most strains are susceptible to erythromycin, penicillin, streptomycin, and chloramphenicol, resistant to furazolidone, resistant or slightly resistant to lysozyme, and weakly resistant to methicillin. Grows well in the presence of up to $5 \% \mathrm{NaCl}$; no growth occurs in the presence of $7 \% \mathrm{NaCl}$. Grows well at 25 to $37^{\circ} \mathrm{C}$. Saprophytic. Nonhemolytic. The type strain is DSM $20448(=$ ATCC $29093=$ CCM 2140). 
Description of the genus Kocuria. Kocuria (Ko.cu'ri.a. M.L. fem. n. Kocuria, named after Miroslav Kocur, a Slovakian microbiologist). The description of the genus Kocuria below is based on data from references $9,22,25-28,43 a, 45$, and 46 and this study. Cells are coccoid. Gram positive. Nonencapsulated. Endospores are not formed. Chemoorganotrophic; metabolism is strictly respiratory. Aerobic; strains of one species are slightly facultatively anaerobic. Catalase positive. Nonhalophilic. Mesophilic. The peptidoglycan type is type L-Lys-Ala ${ }_{3-4}$, variation $\mathrm{A} 3 \alpha$. Mycolic acids and teichoic acids are absent. Galactosamine and glucosamine are the major amino sugars in cell wall polysaccharide. Menaquinones are hydrogenated; the predominant menaquinones are MK- $7\left(\mathrm{H}_{2}\right)$ and $\mathrm{MK}-8\left(\mathrm{H}_{2}\right)$. The polar lipids include diphosphatidylglycerol and phosphatidylglycerol; phosphatidylinositol is present in one species. The major fatty acid is anteiso- $\mathrm{C}_{15: 0}$. The long-chain aliphatic hydrocarbons (br- $\Delta-C$ ) are $C_{24}$ to $C_{29}$ hydrocarbons. The $\mathrm{G}+\mathrm{C}$ content of the DNA ranges from 66 to $75 \mathrm{~mol} \%$ (as determined by the $T_{m}$ method). The type species is Kocuria rosea.

Description of Kocuria rosea (Flügge 1886) comb. nov. (Approved Lists 1980). Kocuria rosea (ro'se.a. L. adj. rosea, rose colored). In addition to the properties given in the genus description above, this species has the following characteristics. Cells are spherical (diameter 1 to $1.5 \mu \mathrm{m}$ ) and occur in pairs, tetrads, and clusters. Colonies are circular, slightly convex, smooth (occasionally rough), and pink or red. No water-soluble exopigment is formed. Colony morphology and color become more distinct with age; cell morphology is not culture age or medium dependent. Growth is stimulated by cysteine and thiamine or cysteine, thiamine, and pantothenic acid. Growth in nutrient broth is followed by moderate turbidity and a deposit; in some strains a surface ring and pellicle are formed. Grows well in the presence of $\mathrm{NaCl}$ concentrations up to $7.5 \%$ $\mathrm{NaCl}$. Oxidase test negative (rarely weakly positive); benzidine test positive. Nitrate reduction positive or weakly positive; nitrite reduction negative. Arginine dihydrolase, phenylalanine deaminase, urease, lecithinase, phosphatase, $\beta$-galactosidase, and bound human and rabbit coagulase negative. Most strains do not grow on inorganic nitrogen agar and on Simmons citrate agar. Hydrolysis of esculin and gelatin is negative; hydrolysis of Tween 80 and starch is variable. Production of acetoin is negative or weak; indole and hydrogen sulfide are not produced. Most strains utilize rhamnose, xylose, and glucitol No acid is formed from mannose, galactose, lactose, and glycerol; acid production from glucose is variable. The optimal growth temperature is in the range from 25 to $37^{\circ} \mathrm{C}$. All strains are susceptible to tetracycline, erythromycin, oleandomycin, novobiocin, methicillin, kanamycin, polymyxin, vancomycin, penicillin G, streptomycin, chloramphenicol, and neomycin. Slightly resistant or resistant to lysozyme. Saprophytic. Nonhemolytic. Isolated from soil and water. The major menaquinone is MK- $8\left(\mathrm{H}_{2}\right)$; MK- $7\left(\mathrm{H}_{2}\right)$ and MK- $9\left(\mathrm{H}_{2}\right)$ are present in minor amounts. The cytochromes are cytochromes $a a_{3}, c_{550}, c_{557}$, $b_{564}$, and $d_{626}$. The predominant fatty acid is anteiso- $\mathrm{C}_{15: 0}$; iso- $\mathrm{C}_{15: 0}$ and $\mathrm{C}_{16: 1}$ occur in smaller amounts. The major aliphatic hydrocarbons (br- $\Delta-C$ ) are $C_{24}$ and $C_{25}$ hydrocarbons. The cell wall polysaccharide amino sugar is galactosamine. The $\mathrm{G}+\mathrm{C}$ content of the DNA is 66 to $75 \mathrm{~mol} \%$ (as determined by the $T_{m}$ method). The type strain is DSM 20447 (= ATCC 186 $=$ CCM 679).

Description of Kocuria varians (Migula 1900) comb. nov. (Approved Lists 1980). Kocuria varians (va'ri.ans. L. part. adj. varians, varying). In addition to the properties given above in the genus description, this species has the following characteristics. Cells are spherical (diameter, 0.9 to $1.5 \mu \mathrm{m}$ ) and occur in tetrads and irregular clusters of tetrads or rarely in packets or as single cells. Colonies are up to $4 \mathrm{~mm}$ in diameter, circular, slightly convex, smooth, and glistening. Some strains may form rough, wrinkled, matt, dry colonies. Colonies are yellow. Does not produce a water-soluble exopigment. Colony morphology and color become more distinct with age; cell morphology is not culture age or medium dependent. Slight turbidity and a deposit occur in nutrient broth. The final $\mathrm{pH}$ in glucose-containing medium is 4.3 to 5.9. Growth occurs on nutrient agar containing up to $7.5 \% \mathrm{NaCl}$ and sometimes occurs on nutrient agar containing $10 \% \mathrm{NaCl}$. Growth is stimulated by methionine or cysteine and thiamine. Oxidase test negative; benzidine test positive. Usually positive for urease and nitrate and nitrite reductases; arginine dihydrolase negative. Free and bound coagulase, $\beta$-galactosidase, phosphatase, lecithinase, phenylalanine deaminase, and DNase negative. Usually grows on Simmons citrate agar but not on inorganic nitrogen agar. Negative for hydrolysis of esculin and Tween 80 . Hydrolysis of starch and gelatin is variable. Production of acetoin is negative or weak; indole and hydrogen sulfide negative. Acid is produced from glucose, xylose, and fructose, but not from mannose, maltose, arabinose, raffinose, galactose, rhamnose, ribitol, lactose, mannitol, glycerol, glucitol, inositol, and salicin. Sucrose utilization is variable. Grows well at 22 to $37^{\circ} \mathrm{C}$. Resistant to lysozyme. Susceptible to kanamycin, neomycin, polymyxin B, and vancomycin; most strains are susceptible to tetracycline, erythromycin, oleandomycin, penicillin G, streptomycin, chloramphenicol, and novobiocin. Very susceptible to methicillin. The major menaquinone is $\mathrm{MK}-7\left(\mathrm{H}_{2}\right)$. The cytochromes are cytochromes $a a_{3}, c_{549}, c_{557}, b_{564}$, and $d_{626}$. The major fatty acid is anteiso- $\mathrm{C}_{15: 0} ; \mathrm{C}_{16: 0}$, iso- $\mathrm{C}_{16: 0}$, and anteiso- $\mathrm{C}_{17: 0}$ occur in smaller amounts. The major aliphatic hydrocarbons (br- $\Delta-\mathrm{C}$ ) are $\mathrm{C}_{25}, \mathrm{C}_{26}$, and $\mathrm{C}_{27}$ hydrocarbons. The major amino sugar in the cell wall polysaccharide is galactosamine. The $\mathrm{G}+\mathrm{C}$ content of the DNA is 66 to $72 \mathrm{~mol} \%$ (as determined by the $T_{m}$ method). Saprophytic. Nonhemolytic. Isolated from mammalian skin, soil, and water. The type strain is DSM 20033 $(=$ ATCC $15306=$ CCM 884).

Description of Kocuria kristinae (Kloos, Tornabene, and Schleifer 1974) comb. nov. (Approved Lists 1980). Kocuria kristinae (kris.ti'nae. M.L. gen. kristinae, of Kristin). In addition to the properties given in the genus description above, this species has the following characteristics. Spheres (diameter, 0.7 to $1.1 \mu \mathrm{m}$ ) occur in tetrads which may form large adherent clusters. Colonies are circular, entire or crenate, convex, smooth or rough, up to $2 \mathrm{~mm}$ in diameter, and pale cream to pale orange; with time the color in the colony center becomes more intense. Colony morphology and color become more distinct with age; cell morphology is not culture age or medium dependent. Does not produce a water-soluble exopigment. Slightly facultatively anaerobic. Grows well on nutrient agar containing up to $10 \% \mathrm{NaCl}$; growth is very weak in the presence of $15 \% \mathrm{NaCl}$. Oxidase and benzidine test positive. Urease variable; arginine dihydrolase, lecithinase, and phosphatase negative; and $\beta$-galactosidase variable. Nitrate reduction is negative in most strains. Nitrite reduction negative. No growth occurs on Simmons citrate agar, and growth does not occur or is weak on inorganic nitrogen agar. Positive for hydrolysis of esculin but negative for hydrolysis of gelatin, Tween 80 , and starch. Produces acetoin. Acid is produced aerobically from glucose, fructose, mannose, sucrose, and glycerol and usually from maltose and glucitol. Does not utilize rhamnose, xylose, ribose, arabinose, raffinose, melibiose, mannitol, ribitol, and galactitol; usually does not utilize galactose and lactose. The amino acid and vitamin requirements are complicated. Usually growth is stimulated by leucine, lysine, valine, tyrosine, and niacin. The optimal growth temperature is 25 to $37^{\circ} \mathrm{C}$. Resis- 
tant to lysozyme. Susceptible to tetracycline, erythromycin, novobiocin, methicillin, penicillin, kanamycin, chloramphenicol, neomycin, vancomycin, polymyxin $\mathrm{B}$, and streptomycin. The major menaquinones are $\mathrm{MK}-7\left(\mathrm{H}_{2}\right)$ and $\mathrm{MK}-8\left(\mathrm{H}_{2}\right)$. The cytochromes are cytochromes $a a_{3}, c_{548}, c_{557}, b_{561}$, and $d_{626}$. The major fatty acid is anteiso- $\mathrm{C}_{15.0} ; \mathrm{C}_{16.0}$, iso- $\mathrm{C}_{16: 0}$, and anteiso$\mathrm{C}_{17: 0}$ occur in smaller amounts. The major aliphatic hydrocarbons (br- $\Delta-C$ ) are $C_{28}$ and $C_{29}$ hydrocarbons. In addition to the genus-specific phospholipids ninhydrin-negative phospholipids and glycolipids are present. The major amino sugar in the cell wall polysaccharide is glucosamine. The $\mathrm{G}+\mathrm{C}$ content of the DNA is $67 \mathrm{~mol} \%$ (as determined by the $T_{m}$ method). Nonhemolytic. The primary habitat is human skin. The type strain is DSM 20032 (= ATCC $27570=$ CCM 2690).

Description of the genus Micrococcus Cohn 1972, $151^{\mathrm{AL}}$ emend. Stackebrandt et al. 1995. The description below is based on characteristics given in references 9, 22, 25, 26, 29, $43 \mathrm{a}, 45$, and 46 and this paper. Cells are spherical and nonmotile. Endospores are not formed. Gram positive. Aerobic. Chemoorganotrophic; metabolism is strictly respiratory. Catalase and oxidase positive. Mesophilic. Nonhalophilic. The peptidoglycan contains L-lysine as the diagnostic amino acid. The peptidoglyan variation is either $\mathrm{A} 2$, with the interpeptide bridge consisting of a peptide subunit, or $\mathrm{A} 4 \alpha$. The predominant menaquinones are either MK-8 and $\mathrm{MK}-8\left(\mathrm{H}_{2}\right)$ or MK$8\left(\mathrm{H}_{2}\right)$; MK-7 or MK- $7\left(\mathrm{H}_{2}\right)$ and MK- $9\left(\mathrm{H}_{2}\right)$ occur in minor amounts. The cytochromes are cytochromes $a a_{3}, b_{557}, b_{567}$, and $d_{626}$; cytochromes $c_{550}, c_{551}, b_{563}, b_{564}$, and $b_{567}$ may be present. Mycolic acids and teichoic acids are absent; teichuronic acids may be present. Mannosamine-uronic acid may be present as an amino sugar in the cell wall polysaccharide. The cellular fatty acids are iso- and anteiso-branched fatty acids, with anteiso- $\mathrm{C}_{15: 0}$ and iso- $\mathrm{C}_{15: 0}$ predominating. The polar lipids are phosphatidylglycerol, diphosphatidylglycerol, and unknown ninhydrin-negative phospholipids and glycolipids; phosphatidylinositol may be present. The major aliphatic hydrocarbons (br- $\Delta-\mathrm{C}$ ) are $\mathrm{C}_{27}$ to $\mathrm{C}_{29}$ hydrocarbons. The $\mathrm{G}+\mathrm{C}$ content of the DNA is 69 to $76 \mathrm{~mol} \%$ (as determined by the $T_{m}$ method). The primary habitat is mammalian skin. The type species is Micrococcus luteus (Schroeter) Cohn 1872, 153 ${ }^{\mathrm{Al}}$.

\section{REFERENCES}

1. Bergan, T., and M. Kocur. 1982. Stomatococcus mucilaginosus gen. nov., sp. nov., ep. rev., a member of the family Micrococcaceae. Int. J. Syst. Bacteriol. 32:374-377.

2. Brooks, W. E., R. G. E. Murray, J. L. Johnson, E. Stackebrandt, C. R. Woese, and G. E. Fox. 1981. A study of the red-pigmented micrococci as a basis for taxonomy. Int. J. Syst. Bacteriol. 30:627-646.

3. Collins, M. D., J. Brown, and D. Jones. 1988. Brachybacterium faecium gen. nov., sp. nov., a coryneform bacterium from poultry deep litter. Int. J. Syst. Bacteriol. 38:45-48.

4. Collins, M. D., and D. Jones. 1980. Lipids in the classification and identification of coryneform bacteria containing peptidoglycans based on 2,4-diaminobutyric acid. J. Appl. Bacteriol, 48:459-470.

5. Collins, M. D., and D. Jones. 1981. Distribution of isoprenoid quinone structural types in bacteria and their taxonomic implications. Microbiol. Rev. 45:316-354.

6. Collins, M. D., T. Pirouz, M. Goodfellow, and D. E. Minnikin. 1977. Distribution of menaquinones in actinomycetes and corynebacteria. J. Gen. Microbiol. 100:221-230.

7. De Soete, G. 1983. A least squares algorithm for fitting additive trees to proximity data. Psychometrica 48:621-626.

8. DSM-Deutsche Sammlung von Mikroorganismen und Zellkulturen GmbH. 1993. Catalogue of strains, 5th ed. DSM-Deutsche Sammlung von Mikroorganismen und Zelikulturen GmbH, Braunschweig, Germany.

9. Faller, A., F. Götz, and K. H. Schleifer. 1980. Cytochrome patterns of staphylococci and micrococci and their taxonomic implications. Zentralbl. Bakteriol. Parasitenkd. Infektionskr. Hyg. Abt. 1 Orig. Reihe C 1:26-39.

10. Felsenstein, J. 1993. PHYLIP (Phylogeny Inference Package), version 3.5c. J. Felsenstein, University of Washington, Seattle.

11. Girard, A. E. 1971. A comparative study of the fatty acids of some micrococci. Can. J. Microbiol. 17:1503-1508.
12. Jantzen, E., T. Bergan, and K. Bøvre. 1974. Gas chromatography of bacterial whole cell methanolysates. VI. Fatty acid composition of strains within $\mathrm{Mi}$ crococcaceae. Acta Pathol. Microbiol. Scand. Sect. B 82:785-798.

13. Jeffries, L. 1969. Menaquinone in the classification of Micrococcaceae with observations on the application of lysozyme and novobiocin sensitivity tests. Int. J. Syst. Bacteriol. 19:183-187.

14. Jones, D., and M. D. Collins. 1986. Irregular, non-sporing Gram-positive rods, p. 1261-1266. In P. H. A. Sneath, N. S. Mair, M. E. Sharpe, and J. G. Holt (ed.), Bergey's manual of systematic bacteriology, vol. 2. The Williams and Wilkins Co., Baltimore.

15. Jones, D., and M. D. Collins. 1988. Taxonomic studies on some human cutaneous coryneform bacteria: description of Dermabacter hominis gen. nov., spec. nov. FEMS Microbiol. Lett. 51:51-56.

16. Jukes, T. H., and C. R. Cantor. 1969. Evolution of protein molecules, p. 21-132. In H. N. Munro (ed.), Mammalian protein metabolism. Academic Press, New York

17. Keddie, R. M. 1974. Arthrobacter, p. 618-625. In R. E. Buchanan and N. E. Gibbons (ed.), Bergey's manual of determinative bacteriology, 8th ed. The Williams and Wilkins Co., Baltimore.

18. Keddie, R. M., D. Collins, and D. Jones. 1986. Genus Arthrobacter, p. 12881301. In P. H. A. Sneath, N. S. Mair, M. E. Sharpe, and J. G. Holt (ed.) Bergey's manual of systematic bacteriology, vol. 2. The Williams and Wilkins Co., Baltimore.

19. Keddie, R. M., and D. Jones. 1981. Aerobic, saprophytic coryneform bacteria, p. 1838-1878. In M. P. Starr, H. Stolp, H. G. Trüper, A. Balows, and H. G. Schlegel (ed.), The prokaryotes. A handbook on habitats, isolation and identification of bacteria. Springer-Verlag, Berlin.

20. Kloos, W. E. 1969. Transformation of Micrococcus lysodeikticus by various members of the family Micrococcaceae. J. Gen. Microbiol. 59:247-255.

21. Kloos, W. E., and K. H. Schleifer. 1986. Staphylococcus, p. 1013-1035. In P. H. A. Sneath, N. S. Mair, M. E. Sharpe, and J. G. Holt (ed.), Bergey's manual of systematic bacteriology, vol. 2. The Williams and Wilkins Co., Baltimore.

22. Kloos, W. E., T. G. Tornabene, and K. H. Schleifer. 1974. Isolation and characterization of micrococci from human skin, including two new species: Micrococcus lylae and Micrococcus kristinae. Int. J Syst. Bacteriol 24:79-101.

23. Koch, C., F. A. Rainey, and E. Stackebrandt. 1994. 16S rDNA studies on members of Arthrobacter and Micrococcus: an aid for their future taxonomic restructuring. FEMS Microbiol. Lett. 123:16-172.

24. Koch, C., and E. Stackebrandt. 1995. Reclassification of Micrococcus agilis (Ali-Cohen 1889) to Arthrobacter as Arthrobacter agilis comb. nov. and emendation of the genus Arthrobacter. Int. J. Syst. Bacteriol. 45:837-839.

25. Kocur, M. 1986. Genus Micrococcus Cohn 1972, p. 1004-1008. In P. H. A Sneath, N. S. Mair, M. E. Sharpe, and J. G. Holt (ed.), Bergey's manual of systematic bacteriology, vol. 2. The Williams and Wilkins Co., Baltimore.

26. Kocur, M., W. E. Kloos, and K. H. Schleifer. 1991. The genus Micrococcus, p. 1300-1311. In A. Balows, H. G. Trüper, M. Dworkin, W. Harder, and K. H. Schleifer (ed.), The prokaryotes. A handbook on the biology of bacteria: ecophysiology, isolation, identification, applications. Springer-Verlag, New York.

27. Kocur, M., and T. Martinec. 1972. Taxonomic status of Micrococcus varians Migula 1900 and designation of the neotype strain. Int. J. Syst. Bacteriol. 22:228-232.

28. Kocur, M., and Z. Pacova. 1970. The taxonomic status of Micrococcus roseus Flügge 1886. Int. J. Syst. Bacteriol. 20:233-240.

29. Kocur, M., Z. Pacova, and T. Martinec. 1972. Taxonomic status of Micrococcus luteus (Schroeter 1972) Cohn 1872 and designation of the neotype strain. Int. J. Syst. Bacteriol. 22:218-223.

30. Kocur, M., K. H. Schleifer, and W. E. Kloos. 1975. Taxonomic status of Micrococcus nishinomiyaensis Oda 1935. Int. J. Syst. Bacteriol. 25:290-293.

31. Larsen, N., G. J. Olsen, B. L. Maidak, M. McCaughey, J. R. Overbeek, T. J. Macke, T. L. Marsh, and C. R. Woese. 1993. The Ribosomal Database Project. Nucleic Acids Res. 21:3021-3023.

32. Lechevalier, M. P., C. de Bievre, and H. Lechevalier. 1977. Chemotaxonomy of aerobic actinomycetes: phospholipid composition. Biochem. Syst. Ecol. 5:249-260

33. Minnikin, D. E., L. Alshamaony, and M. Goodfellow. 1975. Differentiation of Mycobacterium, Nocardia and related taxa by thin-layer chromatographic analysis of whole-organism methanolysates. J. Gen. Microbiol. 88:200-204.

34. Morrison, S. J., T. G. Tornabene, and W. E. Kloos. 1971. Neutral lipids in the study of the relationships of members of the family Micrococcaceae. J. Bacteriol. 108:353-358.

35. Ogasawara-Fujita, N., and K. Sakahuchi. 1976. Classification of micrococci on the basis of deoxyribonucleic acid homology. J. Gen. Microbiol. 94:97-106.

36. Onishi, H., and M. Kamekura. 1972. Micrococcus halobius sp. nov. Int. J. Syst. Bacteriol. 22:233-236.

37. Rainey, F. A., M. Dorsch, H. W. Morgan, and E. Stackebrandt. 1992. 16S rDNA analysis of Spirochaeta thermophila: its phylogenetic position and implications for the systematics of the order Spirochaetales. Syst. Appl. Microbiol. 15:197-202.

38. Rainey, F. A., N. Weiss, H. Prauser, and E. Stackebrandt. 1994. Further evidence for the phylogenetic coherence of actinomycetes with group B- 
peptidoglycan and evidence for the phylogenetic intermixing of the genera Microbacterium and Aureobacterium as determined by $16 \mathrm{~S}$ rRNA analysis. FEMS. Microbiol. Lett. 118:135-140.

39. Rainey, F. A., N. Weiss, and E. Stackebrandt. 1995. A phylogenetic analysis of the genera Cellulomonas, Promicromonospora, and Jonesia and proposal to exclude the genus Jonesia from the family Cellulomonadaceae. Int. J. Syst. Bacteriol. 45:650-652

40. Regensburger, A., W. Ludwig, and K. H. Schleifer. 1988. DNA probes with different specificities from a cloned 23S rRNA gene of Micrococcus luteus. J. Gen. Microbiol. 134:1197-1204.

41. Rupprecht, M., and K. H. Schleifer. 1977. Comparative immunological study of catalases in the genus Micrococcus. Arch. Microbiol. 113:61-66.

42. Saitou, N., and M. Nei. 1987. The neighbor-joining method: a new method for reconstructing phylogenetic trees. Mol. Biol. Evol. 4:406-425.

43. Schleifer, K. H. 1986. Gram-positive cocci, p. 999-1003. In P. H. A. Sneath N. S. Mair, M. E. Sharpe, and J. G. Holt (ed.), Bergey's manual of systematic bacteriology, vol. 2. The Williams and Wilkins Co., Baltimore.

43a.Schleifer, K. H. Personal communication.

44. Schleifer, K. H., W. Heise, and S. A. Meyer. 1979. Deoxyribonucleic acid hybridization studies among some micrococci. FEMS Lett. 6:33-36.

45. Schleifer, K. H., and O. Kandler. 1972. Peptidoglyan types of bacterial cell walls and their taxonomic implications. Bacteriol. Rev. 6:407-477.

46. Schleifer, K. H., W. E. Kloos, and M. Kocur. 1981. The genus Micrococcus, p. 1539-1547. In M. P. Starr, H. Stolp, H. G. Trüper, A. Balows, and H. G. Schlegel (ed.), The prokaryotes. A handbook on habitats, isolation and identification of bacteria. Springer-Verlag, Berlin.

47. Stackebrandt, E., B. J. Lewis, and C. R. Woese. 1980. The phylogenetic structure of the coryneform group of bacteria. Zentralbl. Bakteriol. Parasitenkd. Infektionskr. Hyg. Abt. 1 Orig. Reihe C 2:137-149.

48. Stackebrandt, E., and H. Prauser. 1991. The family Cellulomonadaceae, p. 1323-1345. In A. Balows, H. G. Trüper, M. Dworkin, W. Harder, and K. H. Schleifer (ed.), The prokaryotes. A handbook on the biology of bacteria: ecophysiology, isolation, identification, applications. Springer-Verlag, New York.

49. Stackebrandt, E., C. Scheuerlein, and K. H. Schleifer. 1983. Phylogenetic and biochemical studies on Stomatococcus mucilaginosus. Syst. Appl. Microbiol. 4:207-217.

50. Stackebrandt, E., and C. R. Woese. 1979. A phylogenetic dissection of the family Micrococcaceae. Curr. Microbiol. 2:317-322.

51. Stead, D. E., J. E. Sellwood, J. Wilson, and I. Viney. 1992. Evaluation of a commercial microbial identification system based on fatty acid profiles for rapid, accurate identification of plant pathogenic bacteria. J. Appl. Bacteriol. 72:315-321.

52. Tamura, T., M. Takeuchi, and A. Yokota. 1994. Leucococcus japonicus gen. nov., sp. nov., a new gram-positive coccus with LL-diaminopimelic acid in the cell wall. Int. J. Syst. Bacteriol. 44:348-356.

53. Tornabene, T. G., S. J. Morrison, and W. E. Kloos. 1970. Aliphatic hydrocarbon contents of various members of the family Micrococcaceae. Lipids 5:929-937. 